\title{
Effect of a Comprehensive Total Parenteral Nutrition Training Program on Knowledge and Practice of Nurses in NICU
}

\author{
Zahra Daneshvar Ameri ${ }^{1}$, Ali Vafaee ${ }^{2}$, Tahere Sadeghi ${ }^{3}$, Zhila Mirlashari $^{4}$, Djavad Ghoddoosi-Nejad ${ }^{5}$ \& \\ Faramarz Kalhor ${ }^{2}$ \\ ${ }^{1}$ School of Nursing \& Midwifery, Tehran University of Medical Sciences, Tehran, Iran \\ ${ }^{2}$ Student of Neonatal Critical Care Nursing, Tehran University of Medical Sciences, Tehran, Iran \\ ${ }^{3}$ Mashhad University of Medical Sciences, Iran \\ ${ }^{4}$ School of Nursing and Midwifery, Tehran University of Medical Sciences, Tehran, Iran \\ ${ }^{5}$ Social Determinants of Health Research Center, Birjand University of Medical Sciences, Birjand, Iran \\ Correspondence: Ali Vafaee, Sarem fertility and infertility research center-SAFIR, Sarem Womens's Hospital, \\ Tehran, Iran. E-mail: vafaeeali.nicu@gmail.com
}

Received: January 15, 2016 Accepted: February 4, 2016 Online Published: February 24, 2016

doi:10.5539/gjhs.v8n10p135 URL: http://dx.doi.org/10.5539/gjhs.v8n10p135

\begin{abstract}
Background: Parenteral nutrition is a lifesaving therapy for many infants who are unable to tolerate enteral feedings. It fulfils preterm neonates' needs for growth and development when their sizes or conditions preclude enteral feeding. Virtuous nursing care and close biochemical monitoring are absolutely essential for successful parenteral nutrition therapy. Since poor knowledge in parenteral nutrition can causes severe impairment to neonatal infants, the conduction of this study is essential.
\end{abstract}

Aims: The present study aims to: (1) examine the knowledge and practice of nurses in total parenteral nutrition (TPN); (2) employ training programs for improving knowledge and practice in management of TPN in new-borns.

Method: A quasi-experimental study was carried out in Sarem Maternity Hospital in Tehran, Iran. The study population included nurses working in Neonatal Intensive Care Unit (NICU) who were included in the study using headcount census method $(\mathrm{n}=30)$. A two-part questionnaire including demographic information; 20 multiple choice questions on the nurses' knowledge of TPN therapy and 19-item 3-point Likert-type checklist on administration of TPN completed by observing the nurses' practice. To examine the reliability of the practice part, Cronbach's alpha method was used $(\alpha=0.78)$. Study interventions were mentoring education by the researcher and researcher-developed training manual and educational video and guidelines about neonatal parenteral nutrition. Before and after intervention data were collected and compared using paired t-test.

Results: The mean scores of nurses' knowledge before and afterward parenteral nutrition (PN) training program were $11.93 \pm 1.91$ and $17.56 \pm 1.59$, respectively. The mean scores of the nurses' practice earlier and after training program were $38.84 \pm 2.96$ and $40.15 \pm 3.02$, respectively. Comparing the mean scores of the nurses' familiarity, before and after taking the training course, demonstrated a significant difference $(p<0.0001)$. The knowledge of the nurses in all areas of parenteral nutrition prescription was significantly improved after the employment of mentoring method $(\mathrm{p}<0.05)$. Despite an increase in the post-intervention total score, the nurses' practice, before and after, the intervention was not statistically significant $(\mathrm{p}<0.05)$.

Conclusion: There is a breach between nursing knowledge and practice in prescribing parenteral nutrition. The gap between knowledge and practice in this area can lead to more morbidity and negative influences on the infant. Therefore, it is required that the gap between knowledge and practice is known as the infant gets less damage.

Keywords: parenteral nutrition, nurse, neonatal intensive cares, knowledge, practice 


\section{Background}

Parenteral nutrition is indicated for initiation of nutrition support for premature and high-risk neonates; as it provides nutritional support when enteral intake is not possible or does not provide sufficient caloric requirements. The initial goal of $\mathrm{PN}$ is to minimize losses and preserve existing body stores; it progresses to provide nutrition in order to promote growth and development.

Parenteral nutrition (PN) is a sterile intravenous solution of protein, dextrose and fat in combination with electrolytes, vitamins, trace elements and water. PN for the premature infant includes; (1) adequate calories for energy expenditure and growth, (2) carbohydrates to prevent hypoglycemia and in combination with lipids to provide the caloric intake to meet the energy needs of the infant, (3) adequate protein intake, including essential amino acids, to achieve positive nitrogen balance required for growth, (4) fatty acids to prevent essential fatty acid deficiency and maximize overall non-protein energy intake and (5) essential nutrients including minerals i.e. calcium magnesium, and phosphorus, electrolytes, vitamins, and trace elements (e.g. copper, zinc, and selenium), which are desired for growth (Poindexter et al., 2006).

Nurses' roles in administrating of PN are; assessing patients, fluid balance recording, daily weight of patients, checking of PN prescription, ensuring specific PN solution written, check PN solution, line care and connection/running of intravenous PN infusions (Al-Rafay \& Al-Sharkawy, 2012).

Newborn infants in neonatal intensive care units (NICU), mainly the frail and premature newborns whom are often in need of effective nutritional support. These needs are frequently met by the administration of PN, especially during the early stages of life. The nutrient level of preterm neonates, particularly the extremely low birth weight (ELBW) infants, is rarely adequate to meet their needs (Olsen, Richardson, Schmid, Ausman, \& Dwyer, 2002). As a result, these newborn infants will suffer from serious nutritional deficiencies during post-birth stages (Shamsuddin, 2003). TPN is globally used for infants under 1,500 grams or infants with surgical complications caused by congenital or acquired diseases such as necrotizing enterocolitis (Clark et al., 2003).

TPN in neonates, compared with adults, is a major challenge as the required nutrients and their levels are not standardized and are rather determined based on the infant's weight. In addition, the required electrolytes and glucose level in this group significantly fluctuates particularly within preterm infants (Storm, Young, \& Sandler, 1995).

Parenteral nutrition improves nutritional condition of infants who are small for gestational age. There are however risks such as; sepsis, thrombosis, and many metabolic disorders associated with administration of this treatment. According to the reports, the greatest risks related to TPN- infusion are hypokalemia, hypomagnesemia, hypophosphatemia, hypoglycemia, metabolic acidosis, and hyperammonemia. In addition, leakage of TPN may result in the accumulation of fluid in the pericardial, subdural, and pleura spaces and in some cases, lead to death (Steinbach et al., 2008). Mechanical complications are important as the effects are usually immediate and contribute to an increased length of stay, increased hospital costs, need for subsequent interventions, and mortality rate. These include failure to place the catheter, pneumothorax, arterial puncture, pulmonary embolism, air embolism, dysrhythmia, and death (McGee \& Gould, 2003).

Results from a study in 2004 in the Seattle Children's Hospital did not statement any parenteral nutrient-induced deaths, though on average, there were nine mistakes in every 1,000 parenteral nutrition prescriptions given to the patients with the frequency of 3.5 to 17.5 per month. According to this study, it was determined that the frequency, severity, and extent of medication errors in all hospital wards demonstrated that parenteral nutrition mistakes were considered as risky medication errors (Turpin et al., 2011).

Knowledge and skill of the nurses that administer this therapy are two essential factors in preventing errors. Appropriate nursing care and careful biochemical monitoring are required for a successful parenteral nutrition therapy (Chaudhari \& Kadam, 2006). In addition, appropriate clinical guidelines on relative amounts of the constituents of parenteral nutrition solutions lead to the proper nutritional support and protect the neonates from possible risks of PN therapy (Peverini, Beach, Wan, \& Vyhmeister, 2000). Therefore, development of a training program to improve the knowledge, practice and skills of nurses is the first step towards an improved method and a reduced number of complications.

Despite nurses' academic knowledge on this nutritional technique, nurses still perform poorly. A study in Jamaica showed that despite having the required knowledge, $85 \%$ of the nurses did not carefully observe the safety precautions of nursing practice (Figueroa et al., 2008). Byrd et al. demonstrated that knowledge-practice gap still exists within newborn pain management. Increased caregiver education remains a necessity, but 
strategies that address resistance to change practice within healthcare settings must also be considered (Byrd, Gonzales, \& Parsons, 2009).

On the other hand, the employed training method is also important. Employing academically-educated nurses, as advisors, in a hospital alters the caring methods they use and improves the caring outcomes. The presence of an advisor or instructor will help nurses, under the novice to expert continuum training, complete the course quicker (Latham, Hogan, \& Ringl, 2008).

Mentorship requires an informal, usually face-to-face, communication in a certain period between the trainer and trainee (Andrews \& Chilton, 2000). Personal satisfactions of the trainee, career success, and professional involvement are the advantages of this method (LaFleur \& White, 2010). Since poor knowledge and practice in parenteral nutrition cause irreparable damage to the newborn infants, the conduction of this study seems crucial.

This study aimed at determining the knowledge and practice of nurses in TPN, the advantages of using training programs for improving their practice in caring infants under TPN, in-service training, and minimizing the prescription mistakes and TPN complications.

\section{Method}

This is a quasi-experimental interventional study, in which the pre- and post-intervention data were compared. An approval was obtained from the Ethics Committee of the Tehran University of Medical Sciences. The study population included all nurses working in NICU of Sarem Maternity Hospital. They totally were included in the study using headcount census method $(\mathrm{n}=30)$. A two-part questionnaire including demographic information (in the first part) and 41 questions on the nurses' practice and knowledge about TPN (in the second part) was completed.

The knowledge-related part consists of 22 multiple-choice questions, which was completed by the nurses. The practice part consists of a 19-item checklist on TPN completed by two researchers through observing the nurses' practice in seven days, before practicing the research intervention. Each of these two researchers compared the nurses' practice separately with the prepared checklist and then completed the checklist. One month after the completion of knowledge questionnaire and practice checklist, the nurses underwent a comprehensive training program that included a clinical course using a mentoring method. In this method, by the time the nurses who worked in the NICU started to give parenteral nutrition prescription, they underwent a training course in different areas of TPN as follows: objectives, application, various solutions, prescription methods and steps, precautions to be followed-up, monitoring the infant receiving parenteral nutrition, and TPN recording. These trainings repeated three times for every nurse. All of them received training in all preparation stages, from prescription though monitoring the infant receiving parenteral nutrition. They could ask their questions from the mentor during clinical work. In addition, from the first day of the training, a training manual and a CD were given to them for further review of the contents. One month after the completion of the training course, the knowledge questionnaire was answered by the nurses once again. The practice checklist was also completed by the researchers through observing the practice of the nurses in 7 days. Then, pre- and post-intervention results were also compared.

This questionnaire was prepared by reviewing Parenteral Nutrition Chapter of the Neonatal Intensive Care Nursing, the last update of www.uptodate.com on parenteral nutrition solutions in infants and neonates, and a review article titled "Parenteral Nutrition in NICU" published by the Association of America's Children in 2011. Validity of the questionnaire was obtained using the face validity and content validity methods. Form of the questions and their distribution were adjusted to research objectives, using the opinions of 10 experts as follows: seven NICU nursing instructors, two neonatologists, and one clinical pharmacy specialist. Their opinions were also employed to adapt research objectives with the contents of the questions. To evaluate the reliability of the research instrument, test-retest and Cronbach's alpha techniques were used. To this end, test-retest trial was employed to find the reliability of the knowledge-related multiple choice questions in a one-month interval. To examine the reliability of the 3-point Likert-type practice part, Cronbach's alpha method was used $(\alpha=0.78)$.

The t-test method was used to compare the nurses' knowledge and practice in TPN before and after the intervention. Selection of a hospital for performing the intervention was a limitation of the study, which might affect the results

\section{Results}

Half of the participants were under 30 years of age. All were female, and $60 \%$ of them had less than five years of work experience. In addition, $56 \%$ of them were on shiftwork. In terms of education, $93 \%$ had bachelor degree, and $7 \%$ had master degree. Ninety percent were contractual employees, and $23 \%$ of them had undergone a PN 
training course.

As can be seen in Table 1, the mean scores of the nurses' knowledge before and after the parenteral nutrition were $11.93 \pm 1.91$ and $17.56 \pm 1.59$, respectively. According to the data analysis, the mean scores of the knowledge before and after the completion of the research's training course were significantly different $(p<0.001)$.

The mean scores of the practice before and after parenteral nutrition were $38.84 \pm 2.96$ and $40.15 \pm 3.02$, respectively. According to data analysis, the mean scores of the practice before and after the completion of the research's training course were not significantly different $(\mathrm{p}=0.07)$.

Table 1. Mean scores of the nurses' knowledge and practice before and after parenteral nutrition education

\begin{tabular}{llllll}
\hline & mean & SD & DF & paired t-test & p-value \\
\hline Nursing knowledge before intervention & 11.93 & 1.91 & \multirow{2}{*}{29} & -14.09 & $<0.001$ \\
Nursing knowledge after intervention & 17.56 & 1.59 & & & \\
Nursing practice before intervention & 38.84 & 2.96 & 29 & -1.84 & 0.07 \\
Nursing practice after intervention & 40.15 & 3.02 & & & \\
\hline
\end{tabular}

According to Table 2, none of the demographic information affected the knowledge and practice scores of the nurses, either before or after the intervention.

Table 2. Differences between the nurses' knowledge and practice in parenteral nutrition according to demographic factor

\begin{tabular}{lllll}
\hline variables & knowledge & & practice & \\
\hline & pre & post & pre & post \\
\hline Age & $\mathrm{r}=0.250$ & $\mathrm{R}=0.282$ & $\mathrm{R}=0.210$ & $\mathrm{R}=0.152$ \\
& $\mathrm{p}=0.182$ & $\mathrm{P}=0.132$ & $\mathrm{P}=0.303$ & $\mathrm{P}=0.421$ \\
Job experience & $\mathrm{R}=0.161$ & $\mathrm{R}=0.123$ & $\mathrm{R}=0.204$ & $\mathrm{R}=0.042$ \\
& $\mathrm{P}=0.396$ & $\mathrm{P}=0.517$ & $\mathrm{P}=0.317$ & $\mathrm{P}=0.825$ \\
Education level & $\mathrm{R}=0.062$ & $\mathrm{R}=0.11$ & $\mathrm{R}=0.065$ & $\mathrm{R}=0.182$ \\
& $\mathrm{P}=0.746$ & $\mathrm{P}=952$ & $\mathrm{P}=0.752$ & $\mathrm{P}=0.335$ \\
Employment Type & $\mathrm{R}=0.189$ & $\mathrm{R}=0.092$ & $\mathrm{R}=0.061$ & $\mathrm{R}=0.194$ \\
& $\mathrm{P}=0.316$ & $\mathrm{P}=0.627$ & $\mathrm{P}=0.752$ & $\mathrm{P}=0.303$ \\
Courses of parenteral nutrition education & $\mathrm{R}=0.320$ & $\mathrm{R}=0.294$ & $\mathrm{R}=0.841$ & $\mathrm{R}=0.309$ \\
& $\mathrm{P}=0.484$ & $\mathrm{P}=0.522$ & $\mathrm{P}=0.066$ & $\mathrm{P}=0.499$ \\
Shift & $\mathrm{R}=0.151$ & $\mathrm{R}=0.014$ & $\mathrm{R}=0.222$ & $\mathrm{R}=0.070$ \\
& $\mathrm{P}=0.427$ & $\mathrm{P}=0.943$ & $\mathrm{P}=0.276$ & $\mathrm{P}=0.714$ \\
\hline
\end{tabular}

$*=\alpha$ is significant at 0.05

As can be seen in Table 3, there are significant differences in all eight sub-areas of knowledge after educational intervention. The mean score of the knowledge before and after training indicates that training intervention positively affected all of those areas.

Table 3. Mean scores of the nurses' sub-areas of knowledge before and after parenteral nutrition education

\begin{tabular}{llllll}
\hline \multirow{2}{*}{ Knowledge } & \multicolumn{2}{c}{ Mean \pm SD } & \multirow{2}{*}{ DF } & $\begin{array}{l}\text { Paired } \\
\text { t-test }\end{array}$ & p-value \\
\cline { 2 - 3 } & Pre $(\mathrm{n}=30)$ & Post $(\mathrm{n}=30)$ & & \\
\hline Goal of parenteral nutrition & $0.73 \pm 0.69$ & $1.43 \pm 0.56$ & 29 & $4.82-$ & $<0.00$ \\
Indications of parenteral nutrition & $2.53 \pm 0.62$ & $2.86 \pm 0.43$ & 29 & $2.56-$ & 0.016 \\
Parenteral nutrition solutions & $2.70 \pm 0.70$ & $3.46 \pm 0.86$ & 29 & $3.91-$ & $<0.00$ \\
\hline
\end{tabular}




\begin{tabular}{llllll}
\hline Routes of administration & $0.76 \pm 0.67$ & $2.33 \pm 0.60$ & 29 & $8.83-$ & $<0.00$ \\
$\begin{array}{l}\text { Precautions to follow relating parenteral } \\
\text { nutrition administration }\end{array}$ & $1.36 \pm 0.80$ & $2.56 \pm 0.72$ & 29 & $6.37-$ & $<0.00$ \\
Monitoring for neonates with TPN & $0.86 \pm 0.34$ & $1.00 \pm 0.00$ & 29 & $2.11-$ & 0.043 \\
Documentation & $0.73 \pm 0.44$ & $0.96 \pm 0.18$ & 29 & $2.53-$ & 0.017 \\
Parenteral nutrition complications & $1.40 \pm 0.62$ & $2.00 \pm 0.00$ & 29 & $5.28-$ & $<0.00$ \\
\hline
\end{tabular}

$*=\alpha$ is significant at 0.05

According to Table 4, no significant difference was observed in practical steps of PN before and after research intervention.

Table 4. Mean scores of the nurses' steps practice before and after parenteral nutrition education

\begin{tabular}{|c|c|c|c|c|c|}
\hline \multirow{2}{*}{ Practice } & \multicolumn{2}{|l|}{ Mean \pm SD } & \multirow{2}{*}{ DOF } & \multirow{2}{*}{$\begin{array}{l}\text { Paired } \\
\text { t-test }\end{array}$} & \multirow{2}{*}{ p-value } \\
\hline & Pre $(n=30)$ & Post $(n=30)$ & & & \\
\hline $\begin{array}{l}\text { Error prevention within administration of } \\
\text { TPN }\end{array}$ & $1.58 \pm 11.20$ & $1.49 \pm 11.40$ & 29 & -0.45 & 0.65 \\
\hline $\begin{array}{l}\text { Prevent from infection within } \\
\text { administration of TPN }\end{array}$ & $1.62 \pm 6.16$ & $1.22 \pm 6.26$ & 29 & -0.28 & 0.77 \\
\hline Correct routes of administration & $1.08 \pm 11.93$ & $1.00 \pm 11.86$ & 29 & 0.22 & 0.82 \\
\hline TPN complications monitoring & $1.62 \pm 9.33$ & $1.69 \pm 9.46$ & 29 & -0.47 & 0.63 \\
\hline
\end{tabular}

$*=\alpha$ is significant at 0.05

\section{Discussion}

In this study, the knowledge scores of the nurses in PN were above average (11.93 \pm 1.91$)$. This may be due to the fact that in real-life work situations, the main task of a nurse is to monitor the infant receiving PN in large part of their work shift (Al-Rafay \& Al-Sharkawy, 2012). Similarly, Ista and Josten emphasized that NICUs' nurses play an important role in nutrition of pre-mature children and infants. Nurses should be knowledgeable about many treatment procedures and interventions such as monitoring and caring the neonates during enteral or parenteral nutrition (Ista \& Joosten, 2005).

In this study, knowledge improvement in all areas of parenteral nutrition, including objectives, methods, prescriptive step, complications, prescription precautions, solutions, and recording, showed significant difference before and after the intervention. This is while in Al-Rafay's study, a significant difference was observed in the above-mentioned areas of knowledge, except recording and PN monitoring, before and after the educational intervention. In this regard, he compared his research data with those of Brown's educational intervention in relation to the use of inactive computerized sheets to reduce error rate in PN prescription. He noticed that the application of this method systematically improved the knowledge of senior clinical nurses and pediatric residents and decreased their mistakes in PN prescription (Brown, Garrison, \& Hutchison, 2007).

According to the research findings, the mean scores of the practice before and after parenteral nutrition were $38.84 \pm 2.96$ and $40.15 \pm 3.02$, respectively. According to data analysis, the mean of total scores of the practice, before and after the completion of the research's training course, were not significantly different $(p=0.077)$. In the evaluation of different areas of the practice of participated nurses, no significant improvement was observed in PN prescription mistake prevention, infection prevention, proper methods of practicing $\mathrm{PN}$, and monitoring PN complications; while, in Al-Rafay's study, significant differences were observed in some areas of NICU, including safe prescription and monitoring of mechanical and digestive complications. This may be attributed to the low number of nurse-to-patient ratio, and work and unit related stressors. Taheri et al. showed that the main causes of error in medication prescription in NICU from the nurses' perspective included limited number of staff $(9.26 \%)$, heavy work load $(17.6 \%)$, physical and psychological fatigue $(14.3 \%)$, and hustle and bustle of the ward $(12.6 \%)$, followed by other causes (TAHERI, NOORIAN, RASSOULI, \& KAVOUSI). This is while, in Al-Rafay's research, the overall practice of the nurses after the completion of training course showed a 
significant difference $(\mathrm{p}<0.001)$, which was inconsistent with this study Brown et al. (2007) found that the PN practice score of the nurses was higher than that of pediatric residents. After educational intervention, practice scores of the residents and nurses reached the same level, indicating the effect of such intervention on the practice. This is not consistent with the present study.

Al-Rafay did not found a significant difference in the nurses' practice of in the improvement of metabolic and infectious complications before and after the intervention. The researchers attributed that to the lack of relevant knowledge and low clinical experience. In evaluation of parenteral nutrition prescription practice, Marshall et al. found that the practice of the nurses in this area was not correlated with NICU which can be attributed to the lack of valid and reliable studies on many issues of effective PN. In addition, any change in PN prescription system is another key in the successful implementation of this nutritional method. The implementation of clinical guidance of intravenous injection is not possible without investigating the atmosphere and leadership issues (Marshall, West, \& Aitken, 2011). Kuzma et al. showed that the NICUs where the scores of leadership, personnel coordination, and problem-solving are higher, the rates of nurses' successful practice and their job satisfaction are higher, too (Kuzma-O'Reilly et al., 2003).

In addition, the mere knowledge will not result in attitude and practice development since the environmental facilities and conditions affect the practice. Hilmas et al. attributed the PN prescription errors to three factors: lack of knowledge about optimal prescription of PN solution; the mere knowledge is not a solution and the modification of NICUs for supporting clinical decisions may be required; and finally, frequent phone calls to correct PN prescriptions can reduce the need for caring the patient and mitigate negative effect on the personnel working in pediatric ward and pharmacy (Hilmas \& Partyka, 2004).

Due to the close patient-nurse interactions, nurses play an important role in realizing care objectives, and thus their productivity is very crucial. Achieving high productivity requires that the trainees obtain the maximum amount of knowledge, efficacy, and skills needed for their future career during the training courses. The available clinical trainings do not adequately prepare trainees in achieving clinical competence and skills (Rahmani et al., 2011). In Iran, due to the lack of time or instructors' skills, training is conducted in the form of clinical work and education, and practical education in the presence of a mentor is less practiced (Adib-Hajbaghery, 2009).

Memarian et al. evaluated the monitoring methods training for the nurses working in the men's surgical ward by supervisors trained in the post-operative nursing care documenting. Research findings indicated that after the intervention, the quality of nursing care recording was improved from poor $(\mathrm{p}=0.501, \mathrm{z}=0.663)$ to moderate. The difference in the quality of recording by nurses was significant $(\mathrm{p}<0.05)$. Results showed that a training program through mentorship improved the quality of nursing care recording (Memarian, Vanaki, \& Rahmani, 2013). Therefore, development of a training program to improve the knowledge, practice and skills of nurses is the first step to improve that method and reduce its complications.

\section{Conclusion}

The knowledge of the nurses in all areas of parenteral nutrition prescription was significantly improved after the employment of training program $(\mathrm{p}<0.05)$. Regarding practice, however, despite an increased post-intervention total score, the nurses' practice, before and after intervention, was not statistically significant $(p<0.05)$. The gap between knowledge and practice in this area can lead to increased morbidity and its damaging effects on the infant. Therefore, it is required that the gap between knowledge and practice is known as the infant gets less damage. This demands more attention from the authorities to the effects of training and practical usage of knowledge on the practice of nurses and the reduction of the gap between their knowledge and practice.

\section{Acknowledgements}

The present article is the outcome of a master's thesis in neonatal intensive care nursing in the Tehran University of Medical Sciences.

I gratefully acknowledge the support and generosity of The Sarem Maternity Hospital, without which the present study could not have been completed.

Tehran University of Medical Sciences, Tehran, Iran

The Tehran University of Medical Sciences Ethics Committee approved this study. The ethical number is 9011451015-1

\section{Conflict of Interest}

The authors declare that there is no conflict of interests regarding the publication of this paper. 


\section{References}

Adib-Hajbaghery, M. (2009). Evidence-Based Practice: Iranian Nurses' Perceptions. Worldviews on Evidence-Based Nursing, 6(2), 93-101. http://dx.doi.org/10.1111/j.1741-6787.2009.00149.x

Al-Rafay, S. S., \& Al-Sharkawy, S. S. (2012). Educational outcomes associated with providing a comprehensive guidelines program about nursing care of preterm neonates receiving total parenteral nutrition. Clinical nursing research, 21(2), 142-158. http://dx.doi.org/10.1177/1054773811417314

Andrews, M., \& Chilton, F. (2000). Student and mentor perceptions of mentoring effectiveness. Nurse Education Today, 20(7), 555-562. http://dx.doi.org/10.1054/nedt.2000.0464

Brown, C. L., Garrison, N. A., \& Hutchison, A. A. (2007). Error reduction when prescribing neonatal parenteral nutrition. American Journal of Perinatology, 24(7), 417-427. http://dx.doi.org/10.1055/s-2007-984404

Byrd, P. J., Gonzales, I., \& Parsons, V. (2009). Exploring barriers to pain management in newborn intensive care units: a pilot survey of NICU nurses. Advances in Neonatal Care, 9(6), 299-306. http://dx.doi.org/10.1097/ ANC.0b013e3181c1ff9c

Chaudhari, S., \& Kadam, S. (2006). Total parenteral nutrition in neonates. Indian pediatrics, 43(11), 953-964.

Clark, R. H., Wagner, C. L., Merritt, R. J., Bloom, B. T., Neu, J., Young, T. E., \& Clark, D. A. (2003). Nutrition in the neonatal intensive care unit: how do we reduce the incidence of extrauterine growth restriction? Journal of Perinatology: Official Journal of the California Perinatal Association, 23(4), 337-344. http://dx.doi.org/10.1038/sj.jp.7210937

Figueroa, J., Duncan, J., Byfield, L., Harvey, K., Gebre, Y., Hylton-Kong, T., ... Brathwaite, A. (2008). A comprehensive response to the HIV/AIDS epidemic in Jamaica: A review of the past 20 years. West Indian Medical Journal, 57(6), 562-576.

Hilmas, E., \& Partyka, C. M. (2004). Implementation of computerized parenteral nutrition orders in a community pediatric hospital. American Journal of Health-System Pharmacy, 61(3), 273-277.

Ista, E., \& Joosten, K. (2005). Nutritional assessment and enteral support of critically ill children. Critical Care Nursing Clinics of North America, 17(4), 385-393. http://dx.doi.org/10.1016/j.ccell.2005.07.011

Kuzma-O’Reilly, B., Duenas, M. L., Greecher, C., Kimberlin, L., Mujsce, D., Miller, D., \& Walker, D. J. (2003). Evaluation, development, and implementation of potentially better practices in neonatal intensive care nutrition. Pediatrics, 111(Supplement E1), e461-e470.

LaFleur, A. K., \& White, B. J. (2010). Appreciating mentorship: The benefits of being a mentor. Professional Case Management, 15(6), 305-311. http://dx.doi.org/10.1097/NCM.0b013e3181 eae464

Latham, C. L., Hogan, M., \& Ringl, K. (2008). Nurses supporting nurses: Creating a mentoring program for staff nurses to improve the workforce environment. Nursing Administration Quarterly, 32(1), 27-39. http://dx.doi.org/10.1097/01.NAQ.0000305945.23569.2b

Marshall, A. P., West, S. H., \& Aitken, L. M. (2011). Preferred information sources for clinical decision making: critical care nurses' perceptions of information accessibility and usefulness. Worldviews on Evidence-Based Nursing, 8(4), 224-235. http://dx.doi.org/10.1111/j.1741-6787.2011.00221.x

McGee, D. C., \& Gould, M. K. (2003). Preventing complications of central venous catheterization. New England Journal of Medicine, 348(12), 1123-1133. http://dx.doi.org/10.1056/NEJMra011883

Memarian, R., Vanaki, Z., \& Rahmani, A. (2013). The effect of mentoring program on quality of nursing care recording. Quarterly Journal of Nursing Management, 2(2), 49-54.

Olsen, I. E., Richardson, D. K., Schmid, C. H., Ausman, L. M., \& Dwyer, J. T. (2002). Intersite differences in weight growth velocity of extremely premature infants. Pediatrics, 110(6), 1125-1132. http://dx.doi.org/10. 1542/peds.110.6.1125

Peverini, R. L., Beach, D. S., Wan, K. W., \& Vyhmeister, N. R. (2000). Graphical user interface for a neonatal parenteral nutrition decision support system. Proceedings/AMIA ... Annual Symposium. AMIA Symposium, 650-654.

Poindexter, B. B., Langer, J. C., Dusick, A. M., Ehrenkranz, R. A., Health, N. I. o. C., \& Network, H. D. N. R. (2006). Early provision of parenteral amino acids in extremely low birth weight infants: Relation to growth and neurodevelopmental outcome. The Journal of Pediatrics, 148(3), 300-305. e301. http://dx.doi.org/10. 1016/j.jpeds.2005.10.038 
Rahmani, A., Zamanzadeh, V., Abdullah-zadeh, F., Lotfi, M., Bani, S., \& Hassanpour, S. (2011). Clinical learning environment in viewpoint of nursing students in Tabriz University of Medical Sciences. Iranian Journal of Nursing and Midwifery Research, 16(3), 253.

Shamsuddin, A. F. (2003). Brief history and development of parenteral nutrition support. Mal J Pharm, 1(3), 69-75.

Steinbach, M., Clark, R. H., Kelleher, A. S., Flores, C., White, R., Chace, D. H., \& Spitzer, A. R. (2008). Demographic and nutritional factors associated with prolonged cholestatic jaundice in the premature infant. (Comparative Study Multicenter Study Randomized Controlled Trial). Journal of perinatology: Official Journal of the California Perinatal Association, 28(2), 129-135. http://dx.doi.org/10.1038/sj.jp.7211889

Storm, H. M., Young, S. L., \& Sandler, R. H. (1995). Development of pediatric and neonatal parenteral nutrition order forms. Nutrition in Clinical Practice: Official Publication of the American Society for Parenteral and Enteral Nutrition, 10(2), 54-59.

Taheri, H. E., Noorian, M., Rassouli, M., \& Kavousi, A. (n. d.). Paper: Nurses'Perspectives On Factors Related To Medication Errors In Neonatal And Neonatal Intensive Care Units. http://dx.doi.org/10. $1177 / 011542659501000254$

Turpin, R. S., Canada, T., Liu, F. X., Mercaldi, C. J., Pontes-Arruda, A., \& Wischmeyer, P. (2011). Nutrition therapy cost analysis in the US: Pre-mixed multi-chamber bag vs compounded parenteral nutrition. Applied Health Economics and Health Policy, 9(5), 281-292. http://dx.doi.org/10.2165/11594980-000000000-00000

\section{Copyrights}

Copyright for this article is retained by the author(s), with first publication rights granted to the journal.

This is an open-access article distributed under the terms and conditions of the Creative Commons Attribution license (http://creativecommons.org/licenses/by/3.0/). 